\title{
Blockchain's Roles in Meeting Key Supply Chain Management Objectives
}

\section{By: Nir Kshetri}

Kshetri, Nir (2018)." Blockchain's Roles in Meeting Key Supply Chain Management Objectives," International Journal of Information Management 39, 80-89.

Made available courtesy of Elsevier: https://doi.org/10.1016/i.ijinfomgt.2017.12.005

EY NC ND This work is licensed under a Creative Commons AttributionNonCommercial-NoDerivatives 4.0 International License.

\section{***(C) 2017 Elsevier Ltd. Reprinted with permission. This version of the document is not the version of record. $* * *$}

Abstract:

Arrival of blockchain is set to transform supply chain activities. Scholars have barely begun to systematically assess the effects of blockchain on various organizational activities. This paper examines how blockchain is likely to affect key supply chain management objectives such as cost, quality, speed, dependability, risk reduction, sustainability and flexibility. We present early evidence linking the use of blockchain in supply chain activities to increase transparency and accountability. Case studies of blockchain projects at various phases of development for diverse purposes are discussed. This study illustrates the various mechanisms by which blockchain help achieve the above supply chain objectives. Special emphasis has been placed on the roles of the incorporation of the IoT in blockchain-based solutions and the degree of deployment of blockchain to validate individuals' and assets' identities.

Keywords: Auditability | Blockchain | Internet of things | Network effects | Supply chain | Sustainability

Article:

\section{Introduction}

Blockchain deployment outside finance has been largely experimental. Some of the most promising non-finance applications of blockchain are expected to include those in supply chain, power and food/agriculture. These areas are arguably strong fits for blockchain. These industrial use cases are believed to deliver real ROI at an early stage of blockchain development (Bünger, 2017).

Among many activities that are likely to be transformed by blockchain, supply chain thus deserves special attention. An increasing reliance on the use of Internet-of-things (IoT) applications is among the trends that will affect supply chain management (SCM). With IoT, radio-frequency identification (RFID) tags, sensors, barcodes, GPS tags and chips, the locations 
of products, packages and shipping containers can be tracked at each step. This allows an enhanced, real-time tracking of goods from their origins.

In this regard, for one thing, there is a deep thirst for a foolproof method for confirmed identity in IoT applications. The first of blockchain's direct benefits is that it provides a possible solution to identity management (Alam, 2016). Blockchain can be used in a supply chain to know who is performing what actions. Additionally, time and location of the actions can be determined.

Blockchain facilitates valid and effective measurement of outcomes and performance of key SCM processes. Once the inputs tracking data are on a blockchain ledger, they are immutable. Other suppliers in the chain can also track shipments, deliveries, and progress. In this way, blockchain produces trust among suppliers. By eliminating middleman auditors, efficiency can be increased and costs can be lowered. Individual suppliers can perform their own checks and balances on a near real time basis (Koetsier, 2017).

Blockchain also provides an accurate way of measuring product quality during transportation. For instance, by analyzing data on the travel path and duration, stakeholders in a supply chain can know whether the product was in a wrong place or whether it remained in a location for too long. This is especially important for refrigerated goods, which cannot be left in warm environments. This value proposition is even more appropriate for countries such as China, where meat smuggling has led to serious health risks and a significant loss in tax revenue. In this way, blockchain-based solutions may give the consumers more confidence that the products are genuine and of high quality and make them significantly more willing to purchase the brand.

In order to emphasize the importance of blockchain in food supply chain, the proponents of blockchain offer an example of the 2015 E.coli outbreak at Chipotle Mexican Grill outlets. The crisis left 55 customers ill. The company suffered a reputation loss due to negative news stories, restaurant shutdowns, and investigations. Sales reduced dramatically and its share price dropped by $42 \%$. The roots of the problem lie partly in the reliance of Chipotle and other food companies on multiple suppliers to deliver parts and ingredients. There is a severe lack of transparency and accountability across complex supply chains. Food companies such as Chipotle are not in a position to monitor their suppliers in real time. It is thus impossible for Chipotle to prevent the contamination or contain it in a targeted way after it is discovered (Casey and Wong, 2017). Chipotle's value proposition is centered on fresh and locally sourced ingredients. The nonblockchain methods of securing the Chipotle food supply chain are expensive and cumbersome. The process involves manual verification and massive record keeping. Blockchain can reduce the workload and ensure traceability. Besides the obvious value of traceability, huge benefits can be reaped in terms of reduced labor costs and food wastes. The above examples can be generalized to any industry such as aircraft, electronics or drugs. In short, blockchain-led total value chain visibility can offer huge gains to operations for any firm (O’Marah, 2017).

These benefits accrue to all the parties involved in the supply chain such as the retail warehouses and individual stores. For instance, stores know the details of arrival of a shipment so they are prepared to receive it (Groenfeldt, 2017). In the food product supply chain, for instance, when it is confirmed that a load of apples would arrive at a juice factory, a code is generated and stored remotely. The code is available for verification at any time. Information about the apples and the 
factory that receive them is 'chained' together by this code. Theoretically the data can be portrayed as color-coded maps of inputs, conversion steps and outputs from "farm to fork" (O’Marah, 2017).

Prior researchers have noted various key objectives of supply chain. They include cost, quality, speed, dependability, risk reduction (Baird \& Thomas, 1991;Bettis \& Mahajan,1985), sustainability (Bowen, Cousins, Lamming, \& Faruk, 2001) and flexibility (Goldbach, Seuring, \& Back, 2003; Kovács, 2004, Meyer and Hohmann, 2000, Rao and Holt, 2005, White, 1996). The above discussion suggests that blockchain has a potential to help achieve these objectives.

Some have touted blockchain as the biggest innovation in computer science (Tapscott, 2016). Others consider this technology to be "the biggest disruptor to industries since the introduction of the Internet" (PWCHK.com, 2016). The World Economic Forum (WEF, 2015) considers blockchain to be among six computing "mega-trends" that are likely to shape the world in the next decade. It would be unreasonable to expect that blockchain can transform key supply chain activities. Researchers have begun to grapple with this nascent trend of blockchain deployment in various organizational objectives, but scholars have not systematically assessed the effects of blockchain on supply chain.

In light of the above observations, a key objective of our research is to illustrate blockchain's impact in SCM. To achieve this, we offer a framework ${ }^{1}$ that considers how blockchain can help firms meet key SCM objectives. This article therefore offers the promise of filling many important gaps in the sparse literature on blockchain deployment in supply chain.

The paper is structured as follows. We proceed by first providing a literature review of key supply chain objectives. Next, we discuss the methods employed in the paper. Then, we provide brief descriptions of the selected cases. The section following this looks at the roles of blockchain in achieving various strategic supply chain objectives. It is followed by a section on discussion and implications. The final section provides concluding comments.

\section{Literature review: supply chain objectives}

Logistics services often play a key role in a firm's ability to deliver customer value (Mentzer, Flint, \& Hult, 2001). Among the key goals of an effective logistics within supply chain management involves getting the product in the right condition, in a timely manner and at the lowest possible costs (Flint, 2004). Measurement of supply chain management performance is often described in terms of objectives such as quality, speed, dependability, cost and flexibility (Kovács, 2004, Meyer and Hohmann, 2000, Rao and Holt, 2005, White, 1996).

In addition to the above objectives, prior researchers have addressed the role of supply chain management for sustainable products, which has become a notable research area in marketing and supply chain management (Bowen et al., 2001). This trend is partly driven by consumers' increasing concern about the source of their food and beverages (Scott, 2017). Quak and de Koster (2007) looked at retailers' sustainability policies in logistics by focusing on social and environmental issues such as those related to noise pollution, congestion, and carbon dioxide emissions. Prior researchers have also argued that sustainability-related issues in supply chain, 
which often deal with natural environment and social causes are less quantifiable (Linton, Klassen, \& Jayaraman, 2007).

Global supply chains are complex and face multiple uncertainties (Manuj \& Mentzer, 2008). A major objective of supply chain management is also to reduce risks. Among the various risks that organizations face include relational risks such as a business partner's engagement in opportunistic behavior (e.g., cheating, distorting information) (Baird \& Thomas, 1991;Bettis \& Mahajan, 1985). According to Svensson (2000), the sources of risk in supply chains can be classified into two main categories, namely, atomistic or holistic. In order to deal with atomistic sources of risk, a selected and limited part of the supply chain need to be looked at in order to assess risk. This approach is suitable for components and materials that are of low-value, less complex, and easily available. On the other hand, holistic sources of risk require an overall analysis of the supply chain in order to assess risk. This approach is preferable for high-value, complex, and rare components and materials (Svensson, 2000).

To achieve the various objectives noted above, it is important to evaluate suppliers. Due to increased competition, globalization and outsourcing, the number of players in a typical supply chain has increased significantly. In response, firms have introduced supplier evaluation programs using environmental and social criteria (Beske, Koplin, \& Seuring., 2008; Koplin, Seuring, \& Mesterharm, 2007). Some use supplier self-evaluation, in which supply chain partners declare how they have tackled environmental and social issues (Trowbridge, 2001).

\section{Method}

The approach of this study can be described as theory building from multiple case studies, which is becoming increasingly popular in social science (Eisenhardt and Graebner, 2007, Kshetri, 2016a, Kshetri, 2016b). Compared to a single-case study, multiple-case studies are likely to provide a stronger base for theory building (Rowley, 2002, Yin, 1994).

Connection with related literatures, establishment of theoretical gap that exists in the literature, and explicit statement of research questions to address the gap are the key features of strong empirical research (Eisenhardt \& Graebner, 2007). In qualitative research, it is also important to make a strong case for the importance of the research questions that have been raised (Bansal \& Corley, 2012). We have established theoretical and practical importance of research on the use of blockchain in supply chain.

There has been a good deal of debate on whether case research should be based on theory specified a priori or on grounded theory. Whyte (1984) argues that, to be valuable, research should be guided by" good ideas about how to focus the study and analyze those data" (p. 225). On the contrary, Glaser and Strauss (1967)suggested that evolution of a theory from the data is the basis for development of grounded theory rather than an imposition of a priori theory. Likewise, Van Maanen, Dabbs, and Faulkner (1982, p. 16) suggested that investigators avoid prior commitment to any theory. In this study, we follow Whyte's approach. As such, in order to guide the focus of the study we provide a theoretical framework related to key objectives of supply chain management. 


\subsection{Selection of cases}

Broadly speaking the selection of cases in multiple case study research has the same objectives as in random sampling. That is, the cases should represent the population and there needs to be a useful variation on the dimensions of theoretical interest (Seawright \& Gerring, 2008). A key difference is that in a multiple case study design, the choice of cases needs to be made more on a substantive rather than statistical basis in order to adequately represent a target population (Greene \& David, 1984).

First, it is important to make it clear that case selection is also guided by pragmatic, logistical and financial reasons (Seawright \& Gerring, 2008). We selected only cases for which we could obtain sufficient information from secondary resources. Eisenhardt and Graebner (2007) suggested that about seven cases would be ideal for building theory. In this study, we have selected eleven cases. In order to select the cases, we combined two methods: extreme case method, and diverse case method (Seawright \& Gerring, 2008). More specifically, the process started with extreme case method and morphed over time with implementation of different requirements and recommendations.

In the extreme case method, cases with extreme values on the independent $(\mathrm{X})$ or dependent variable (Y) of interest are selected (Seawright \& Gerring, 2008). The cases selected in this paper are extreme in the sense that they are the earliest adopters of this technology in supply chain. Seawright and Gerring (2008) suggest that if the researcher has some idea about additional factors that might have effect on $\mathrm{Y}$ (the outcome of interest), it would be better to pursue other case selection methods.

Following this recommendation, we utilize a diverse case method as a strategy to select specific cases of firms deploying blockchain in supply chain management. A key objective in this method is to achieve maximum variance along relevant dimensions (Seawright \& Gerring, 2008). This method requires the selection of two or more cases to represent the full range of values characterizing X, Y, or some relationship between these variables (Seawright \& Gerring, 2008).

As to the factors affecting $\mathrm{Y}$, especially the incorporation of the IoT emerged as a key driving factor to achieve key organizational goals. Prior researchers have noted that the blockchain-IoT combination is powerful and is set to transform many industries (Christidis and Devetsikiotis, 2016, Kshetri, 2017a, Kshetri, 2017b). For instance, IoT devices can carry out autonomous transactions through smart contracts (Cognizant Reports, 2016). Combining with artificial intelligence (AI), and big data solutions, more significant impacts can be produced.

An emerging killer blockchain app arguably is digitally signed documents' secure storage and transmission. A key benefit of blockchain is that highly secure audit trails can be used to monitor user activities with the highest possible details. These are being used in trade finance, shipping, and insurance in order to validate the identity of individuals and assets (Mainelli, 2017). The degree of deployment of blockchain to validate individuals' and assets' identities is thus used as another variable to select the cases. 
A key point that needs to be emphasized here is that while IoT devices are one of the major means to validate identities, this process does not necessarily require IoT deployment. That is, validation of identities can be performed with information that may have come from non-IoT sources.

In order to achieve diversity, we selected cases with different combinations of incorporation of the IoT and deployment of blockchain to validate individuals' and assets' identities. It is also worth noting that the variables related to these factors are continuous. As suggested by Seawright and Gerring (2008) for such variables, we chose cases that represent the four different combinations of incorporation of the IoT and deployment of blockchain to validate individuals' and assets' identities as shown in Table 1.

Table 1. The cases selected and their classification in terms of incorporation of the IoT and deployment of blockchain to validate individuals' and assets' identities.

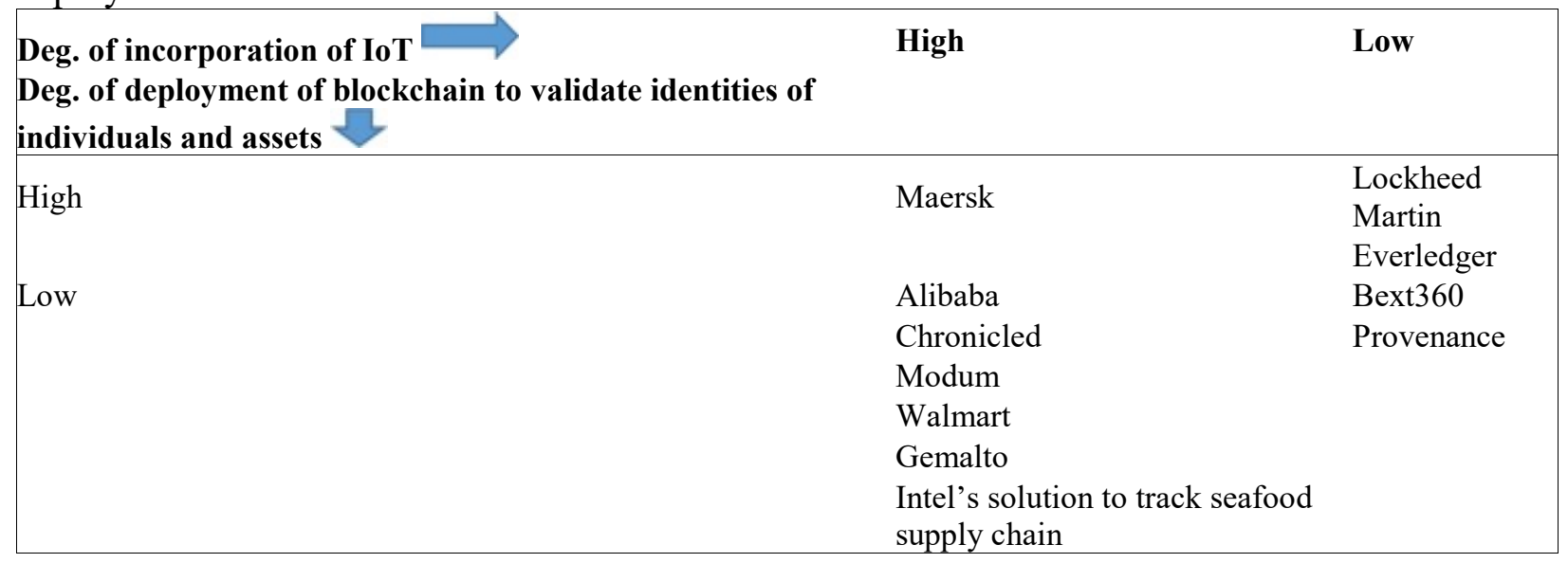

Table 1 presents the cases selected and their classification in terms of incorporation of the IoT and deployment of blockchain to validate individuals' and assets' identities. Seven replicated cases have been used which involve a high degree of incorporation of the IoT. These replicated cases have various degrees of deployment of blockchain to validate individuals' and assets' identities.

Four replicated cases were selected which involve a low degree of incorporation of the IoT. As are the cases involving a high degree of incorporation of the IoT noted above, the replicated cases involving a low degree of incorporation of the IoT also have high and low degrees of different attributes of interest.

\subsection{Sources and characteristics of data}

Prior researchers have identified various dimensions of data quality, which are central to obtaining valid and reliable results (Golder, 2000, Gottschalk, 1969; Mason, McKenney, \& Copeland, 1997). For instance, Gottschalk (1969) suggested that the sources of evidence as well as the evidence need to be evaluated using criteria such as time elapsed between events and reporting, openness to corrections, range of knowledge and expertise of the person reporting the events, and corroboration from multiple sources. Regarding the last point, previous researchers 
have recommended that data and information be triangulated from multiple sources (Constantino \& Westberg, 2009).

First, it is important to make clear that this study mainly relies on archival data, which is among a variety of recognized data sources for case studies (Eisenhardt \& Graebner, 2007). For instance, Ansari, Garud, and Kumaraswam (2015) mainly relied on archival data sources to examine how the digital video recorder TiVo, dealt with the disruptor's dilemma by adjusting its strategy, technology platform, and relation with various players in the TV industry ecosystem. As noted above, this choice is due to pragmatic, logistical and financial reasons (Seawright \& Gerring, 2008) as well as consideration related to ease with which data can be located and gathered (Stvilia, Gasser, Twidale, \& Smith, 2007; Wang \& Strong, 1996).

We made attempts to assess the coherence and internal consistency of the data. As suggested by prior researchers (HIQA, 2011), we evaluated coherence by comparing different data items for the same point in time and the same data items for different points in time. For instance, for Maersk various steps and processes associated with deploying blockchain were compared for 2014 (tracking a shipment of avocados and roses from East Africa to Europe in order to understand the physical processes and paperwork related to shipments in cross-border trades), 2016 (POC to track a container of flowers from Mombasa to Rotterdam in the Netherlands) and 2017 (pilot project that started with Schneider Electric's empty container in Lyon) to ensure that there are logical patterns.

A key dimension of data quality is reputation and trustworthiness. The idea here is to make sure that the source as well as content of data are trustworthy (Wang \& Strong, 1996). A related characteristic is objectivity. That is, the data are unbiased and impartial (Wang \& Strong, 1996). This is related to accuracy or correctness. The goal is to make sure that the information is free from distortion and bias (Eppler, 2006). Another key point that must be considered is an accurate mapping of the real-world phenomenon (Price \& Shanks, 2005). In order to achieve these various goals, among other things, as noted above, we corroborated data and information from multiple sources. We also mostly relied on information reported by reputable third parties instead of taking descriptions directly from the websites of organizations chosen. It minimized potential self-reporting bias.

Another consideration is the timeliness and currency of the data (Wang \& Strong, 1996). Case study researchers need to make sure that the information is up to-date and not obsolete (Eppler, 2006). In this regard, we made sure that the age of the data was appropriate to study the cases selected. We followed the latest news items that were related to the cases chosen. In addition, we visited the websites of the relevant companies.

\section{Brief descriptions of the selected cases}

\subsection{Case 1: maersk}

The Danish shipping company Maersk is the world's largest container carrier and accounts for $18 \%$ to $20 \%$ of the market (Groenfeldt, 2017). Maersk has been a high-profile example of a company that has successfully tested the use of blockchain applications in international logistics. 
Maersk uses the solution to track its shipping containers around the world with attributes like GPS location, temperature, and other conditions (Jackson, 2017).

For many years, Maersk had been looking for a better way to trace the goods it ships worldwide. For Maersk, the key problem was the "mountains of paperwork" required with each container. For instance, Maersk's storage room at Mombasa office, on the coast of Kenya was reported to have shelves and shelves of paper records that date back to 2014 (Popper \& Lohr, 2017).

The chairman of IBM Europe, Erich Clementi personally pitched blockchain to the top technology executive at Maersk. Maersk and IBM started working on a version of its software that would be open to everyone involved with every container. When customs authorities signed off on a document, they could immediately upload a copy of it with a digital signature. This allows everyone involved - including Maersk and government authorities - to see that it was complete. If there were disputes later, everyone could go back to the record and be confident that no one had altered it in the meantime. The cryptography involved would make it hard for the virtual signatures to be forged (Popper \& Lohr, 2017). The solution is based on the Linux Foundation's open source Hyperledger Fabric.

In 2014, Maersk tracked a shipment of avocados and roses from East Africa to Europe in order to understand the physical processes and paperwork in cross-border trades (Baipai, 2017). In most cases, the containers can be loaded on a ship in a few minutes. However, it can be held up in port for many days due to a missing paperwork. The study found that a single container to handle a simple shipment of refrigerated goods from East Africa to Europe required stamps and approvals from up to 30 people such as those in customs, tax officials and health authorities. That includes over 200 different interactions and communications among them (Groenfeldt, 2017).

The goods inside the containers may spoil. It was noted that moving and keeping track of all the required paperwork may cost as much as the cost of physically moving the containers. Frauds are rampant in the global supply chain system. For instance, the bill of lading is often tampered with or copied. Criminals take goods from the containers. They also circulate counterfeit products, which results in billions of dollars in maritime fraud every year.

IBM and Maersk did a proof of concept (POC) in September 2016, which tracked a container of flowers from the Kenyan coast city of Mombasa to Rotterdam in the Netherlands. In the POC, the shipping cost was $\$ 2000$ and the paperwork was estimated at about $\$ 300$ (15\% of the cargo's value) (Groenfeldt, 2017). The POC was considered to be a success. Maersk and IBM followed up by using the system to track containers with pineapples from Colombia, and mandarin oranges from California (Popper and Lohr, 2017).

Subsequently a pilot project was completed in February 2017, which started with Schneider Electric's empty container in Lyon, France. It was then filled with goods from the plant in the location and sent to Rotterdam. In Rotterdam, the container was loaded onto a Maersk Line ship and transported to the Port of Newark in the U.S. From there it was sent to a Schneider Electric facility in the U.S. The number of agencies that participated in the pilot gives an idea of the complexity of international shipping. The agencies included Customs Administration of the Netherlands, the U.S. Department of Homeland Security Science and Technology Directorate, 
and U.S. Customs and Border Protection. Maersk's supply chain solutions company Damco supported origin management activities of the shipment (Groenfeldt, 2017). Rotterdam and Newark were selected with guidance from Maersk. Maersk was able to bring in customs to test the solution (Groenfeldt, 2017). The project is expected to go into production by the end of 2017 (cointelegraph.com, 2017).

\subsection{Case 2: Provenance}

Provenance conducted a pilot project in Indonesia to enable the traceability in the fishing industry. By using mobile phones, blockchain and smart tagging, Provenance tracked fish caught by fishermen. The pilot successfully tracked fish in Indonesia for the first six months of 2016.

The sustainable tracking systems are largely based on papers and reports. Seafood trades source from hundreds of boats, which makes the full quality control a challenging task. There is a lack of supervision. Countries in the region such as Indonesia are also characterized by corruption in the yellow fin tuna industry. This industry is characterized by questionable practices. The industry is plagued by problems such as overfishing, fraud, as well as illegal, unreported, and unregulated (IUU) fish. There are also human rights abuses (Hannam, 2017).

Blockchain can help consumers track the source of their food and address the key challenges noted above. Being the world's largest tuna-producing country, Indonesia provides a fertile ground for testing the technology in order to drastically increase transparency in fish and seafood supply chains. Blockchain-based projects can verify social sustainability claims.

This system's huge potential stems from the fact that seas in the Asia Pacific region provide daily food and income for over 200 million people in Southeast Asia. Southeast Asia accounts for $90 \%$ of seafood consumed in the U.S. Commercial launch of the technology has a potential to stop unethical and illegal practices in the industry including slavery.

\subsection{Case 3: Alibaba}

Alibaba teamed up with AusPost, Blackmores, and $\mathrm{PwC}$ to explore the use of blockchain to fight food fraud, which involves selling lower-quality foods and often with counterfeit ingredients. The four companies aim to develop a "Food Trust Framework" in order to help improve integrity and traceability on the global supply chains. They are working to develop a pilot blockchain solution model that participants across the supply chain can use (Bindi, 2017).

\subsection{Case 4: Lockheed Martin}

In April 2017, the world's largest defense contracting firm, Lockheed Martin announced plans to leverage blockchain in its operations. In order to integrate blockchain into its supply chain risk management, Lockheed Martin teamed up with Virginia-based GuardTime Federal. The deal came two years after the two firms started to work on cybersecurity-related initiatives (Higgins, 2017b).

\subsection{Case 5: Chronicled}


San Francisco-based Blockchain startup Chronicled and life sciences supply chain consultancy LinkLab announced that they launched a "track and trace" pilot for the pharmaceutical industry. This industry is projected to grow to a $\$ 1.12$ trillion industry by 2022 (Prnewswire, 2017). The pilot launched a blockchain-based compliance protocol to satisfy the Drug Supply Chain Security Act (DSCSA).

\subsection{Case 6: Modum}

The Swiss start-up Modum teamed with the University of Zurich to design a system to ensure the safe delivery of pharmaceutical drugs. Most medicines need to be transported under exact temperature, humidity and light conditions in order to ensure usability. Modum's sensors constantly measure these conditions on drugs that are being transported. Under the current system, cargoes involve many people and a lot of paperwork, which can be tampered with (Allen, 2017). Modum's solution aims to address these issues.

A recent regulatory change in the EU, known as Good Distribution Practice of Medicinal Products for Human Use (GDP 2013/C 343/01) requires companies to report any deviations in temperature or other conditions to the distributor as well as the recipient of the affected medicinal products. Currently the only way to comply with the new regulations would be to use refrigeration trucks that make up a significant part of cold chain distribution. These trucks are often four to eight times more expensive than normal logistic services. However, $60 \%$ of about 200 million yearly shipments in the EU do not contain products that are temperature sensitive. This means that an estimated $\$ 3$ billion is wasted annually for unnecessary cooling (Campbell, 2016).

There reportedly are three categories of temperature that medicines need to be stored at: cold $\left(-20{ }^{\circ} \mathrm{C}\right)$, cool $\left(2^{\circ}-{ }^{\circ} \mathrm{C}\right)$, and ambient $\left(15^{\circ}-25^{\circ} \mathrm{C}\right)$. Every medicine, however, has so called "'stability data", which states that the medicine "can stay for $\mathrm{X}$ hours in temperature range $\mathrm{Y}$, [which is] usually $72 \mathrm{~h}$ between $2{ }^{\circ} \mathrm{C}$ and $40{ }^{\circ} \mathrm{C}$ " (Campbell, 2016). Modum is focusing on the ambient products. Medicinal shipments that do not require refrigeration are tracked with a Modum sensor to monitors the temperatures of the medicines. This means that no cold chain truck is required. When the medicine reaches the destination, the data is transferred to the Ethereum blockchain. A Solidity-based smart contract compares the data against various regulatory requirements (Campbell, 2016). If all the required conditions are fulfilled, the product is released. If the temperature and other tracked conditions deviate significantly from the regulatory requirements, the sender and the receiver are notified of the deviation. Modum conducted its first pilot project in June 2016 (Campbell, 2016).

\subsection{Case 7: Everledger}

The London-based startup Everledger's blockchain-based solutions are used to verify provenance of products. It was first used for rough-cut diamonds. The system can be considered to be a digital expression of the Kimberley Process (KP) (Clancy, 2017). Note that the KP is an initiative jointly undertaken by governments, industry and civil society to eliminate the flow of 
diamonds mined within conflict zones such as Sierra Leone that are used by rebel movements to finance wars against legitimate governments (Kimberly Process, 2016).

Everledger has also developed blockchain-based system to track wines. Everledger's tamperevident RFID tag is attached on the bottle's cork. The diamond industry uses a certificate system. For older wines, factors such as a label's design and paper used by a producer in the stated year of production are used in the authentication (Mathieson, 2017). In December 2016, wine expert Maureen Downey and Everledger recorded the first certification of a 2001 bottle from French producer Chateau Margaux. Downey's company Chai Consulting and Everledger developed Chai Wine Vault system for this purpose (https://www.winefraud.com/chai-wine-vault/). The IBM-based ledger gives each bottle a unique digital identity with over 90 pieces of data related to ownership and storage history. The data include high resolution photographs and information from the label, capsule, cork and glass (Rothschield, 2016). As the wine bottle moves along different participants in the supply chain, digital data is updated with ownership and storage records. To verify provenance, retailers, warehouses, auction houses and other sale platforms can link the bottle to its digital identity. Authentication certificates can be kept private or they can be made public for marketing purposes.

It was reported that counterfeiters had reverse-engineered the Coravin system so that they can refill a bottle. As of December 2016, Downey's company was in the process of developing a tamper-proof tag with a chip that detects and registers when a bottle's cork is pulled, or when it is pierced by a system such as Coravin. ${ }^{2}$ The ID of such bottle will not "check in" when logged into the system (Rothschield, 2016).

Everledger's system did not track factors such as bottle temperature. The organization argued that the reputation of the organization storing the wine was sufficient (Mathieson, 2017).

\subsection{Case 8: Walmart}

In the late 2016, it was reported that Walmart was trial-testing a service it developed with IBM to monitor produce in the U.S. and pork in China. The first project involved tracking produce from Latin America to the U.S. The second involved moving pork products from Chinese farms to Chinese stores. As of February 2017, it had completed the two pilots with IBM. Walmart was reported to be confident that a finished version can be ready "within a few years" (Popper \& Lohr, 2017).

Blockchain enabled to digitally track individual pork products in a few minutes compared to many days taken in the past. Details about the farm, factory, batch number, storage temperature and shipping can be viewed on blockchain. These details help assess the authenticity of products, and the expiry date. In the case of food contamination, it is possible to pinpoint the products to recall (Yiannas, 2017).

While the test was limited to these two items, it involved multiple stores. If an item is found to be spoiled or the source of a product is shown to be compromised, the system acts proactively. The goal thus is to improve food safety. The information tracked includes the farm where the 
vegetable or pig originated and their operating practices. RFID tags, sensors and barcodes, which are already widely used across many supply chains, provide the relevant data (Kharif, 2016).

On May 31, 2017, Walmart released the results of the food safety and traceability protocols test that started in October 2016 in China and the U.S. Walmart reported that blockchain helped to reduce the time taken to track food from days to minutes (Higgins, 2017a). Specifically, the tests performed on Chinese pork, and U.S. mangoes revealed that tracing food origins could be handled in $2.2 \mathrm{~s}$, which used to take many weeks with non-blockchain technologies (Nation, 2017).

Blockchain has important cost-saving implications for the retailer. In crisis involving contaminated food products, Walmart would be able to easily identify the source and engage in strategic removals of affected products instead of recalling the entire product line. Blockchain also enables more effective response if tainted products are discovered. In this way, the company can keep buyers' confidence in other products and avoid the danger of consumers getting ill (De Jesus, 2016).

In May 2017, Walmart filed a patent application with the US Patent and Trademark Office (USPTO) entitled "Unmanned Aerial Delivery to Secure Location" (Coggine, 2017). In addition to blockchain's role in package authentication and tracking, Walmart has outlined its plans to incorporate the technology in authenticating a customer and a courier, measuring the temperatures containers and products and comparing with acceptable thresholds and other purposes.

\subsection{Case 9: Gemalto}

Gemalto has teamed up with an insurance company that covers the delivery of temperaturesensitive medicines from drug manufacturer to hospitals located in hot climates. Digital thermometers are used to record the temperature of drugs regularly. This data is added on a blockchain ledger. The responsibility and accountability shift at many points along the supply chaal drugs are delivered in a state that meet regulatory and oin. Blockchain helps to govern that process and provide assurance that the pharmaceuticther requirements. Blockchain helps to make sure that each party in a supply chain oversees its own dataset. Relevant data are, however, shared with other parties (Mathieson, 2017).

\subsection{Case 10: Intel's solution to track seafood supply chain}

In April 2017, Intel revealed a public demo that explains how a seafood supply chain can be tracked using its open-source Sawtooth Lake codebase (https://01.org/sawtooth/). In order to help ensure that different parties comply with food storage conditions, the seafood traceabilty project, dubbed as "The ocean-to-table movement" aims to increase accuracy of record-keeping from the time a fish is caught (Del Castillo, 2017a). Data for four transactions from October 2016 was also made public at the Traceability Blockchain website (https://provenance.sawtooth.me/\#). The data included the record where a fisherman registered the fish upon catch and then sold it to a fishmonger, IoT telemetry and temperature data associated with the journey from the ocean to the fishmonger's store, the fishmonger's record of 
selling to a seafood restaurant and IoT telemetry and temperature data associated with the journey from the fishmonger to the seafood restaurant.

\subsection{Case 11: Bext360}

Denver-based startup Bext360's app and cloud-based software employ Stellar blockchain to record timestamps and value of transactions on a real-time basis. The parties in the transaction such as companies, farmers, and co-ops make data transparent. It creates records of the origination of coffee beans. The system also creates a record of who paid how much. In this way, it is expected to bring complete transparency in the coffee supply chain. The system is expected to be used in other commodities such as cocoa (Kolodny, 2017).

Bext360's first venture will be a kiosk, where farmers can sell beans. The system uses smart image recognition technology that evaluates the crops that are being submitted at production facilities. The system relies on machine learning to categorize the grade and assign a price. A mobile robot allows coffee buyers to assess the quality and weights of a farmer's product in the field. The involved parties can negotiate a fair price through a mobile app (Scott, 2017). It also determines the identity of the person selling the product. The farmers are paid via a mobile app (Clancy, 2017). Bext360's API tool allows intermediaries such as wholesalers and retailers to embed the technology into their websites, marketing, point-of-sale and supply chain management systems.

Using Stellar's application, a digital wallet is assigned to each farmer, machine owner and the machine itself. The information in the transaction tool (a digital wallet) is used to pay for goods collected and loans for the machine. Stellar's application ensures secure and transparent payments directly to the farmers when their products are evaluated and sold. Among other benefits, it helps accurately process payments and credits. Farmers are paid in real time.

\section{The roles of blockchain in achieving various strategic supply chain objectives}

Table 2 provides illustrative examples of how blockchain can contribute to key supply chain management objectives such as cost, quality, speed, dependability, risk reduction, sustainability and flexibility. While some of these examples related to only one of the mechanisms noted above (incorporation of the IoT or validation of identities of individuals and assets), others are combinations of both the mechanisms.

In well-done case study research, framework, theory and data are likely to be "patternmatched" (Eisenhardt \& Graebner, 2007). In this regard, Table 2 provides a visual theory summary, matching with the cases, to explain how the framework developed can be applied to understand the roles of blockchain in meeting key SCM objectives. As suggested by prior researchers (Eisenhardt and Graebner, 2007, Whetten, 1989), the arguments are based on the cases (Table 1) or from other detached logical reasoning and knowledge (cases not listed in Table 1 or other contexts such as Chipotle). 
Table 2. The roles of blockchain in achieving the various strategic supply chain objectives.

\begin{tabular}{|ll|}
\hline $\begin{array}{l}\text { Supply chain } \\
\text { performance } \\
\text { dimension }\end{array}$ & Blockchain's roles \\
\hline Cost & $\begin{array}{l}\text { Economic sense to generate a blockchain code eve } \\
\text { for small transactions. }\end{array}$ \\
& $\begin{array}{l}\text { Crisis involving defective products (e.g., } \\
\text { contaminated food): easily identify the source and } \\
\text { engage in strategic Removals of affected products } \\
\text { instead of recalling the entire product line } \\
\text { Allocate just the right amount of resources to } \\
\text { perform shipping and other activities } \\
\text { Elimination of paper records }\end{array}$ \\
\hline
\end{tabular}

Regulatory compliance costs can be reduced.

Mechanisms involved [Case Number].

Zero or low marginal costs to generate blockchain code if technologies such as IoT have already been used to detect, measure, and track key SCM processes [8].

Detection, measurement, and tracking of key SCM processes with IoT [8].

Detection, measurement, and tracking of key SCM processes with IoT [6].

Digitally signed documents' secure storage and transmission can validate the identities of individuals and assets [1].

Auditable data can be provided to satisfy regulators $[5,9]$.

Supply chain partners are not able to use low quality A tool to improve integrity and traceability in the and counterfeit ingredients

food supply chains to fight against low quality and counterfeit products [3].

Can provide data that can be used to assess useful, Data related to temperature, humidity, motion, light meaningful and representative indicators for describing quality.

Speed $\quad$ Speed can be increased by digitizing physical process and reducing interactions and communications.

conditions, chemical composition from IoT devices or sensors on equipment $([6,10]$.

Digitally signed documents' secure storage and transmission can validate the identities of individuals and assets and minimize the needs of physical interactions and communications [1].

Dependability Supply chain partners can expect a high level of Can be integrated with applications such as mobile dependability of measurement for various indicators robot (e.g., Case 11: Bext360's coffee supply chain) such as quality and weights

Exerting pressure on supply chain partners to be Digitally signed documents' secure storage and more responsible and accountable for their actions. transmission can validate the identities of individuals, which makes it possible to know who is performing what actions, when and where [9].

Blockchain-based digital certification as a means of Supply-chain certification processes to verify increasing dependability.

Detection, measurement, and tracking of key SCM

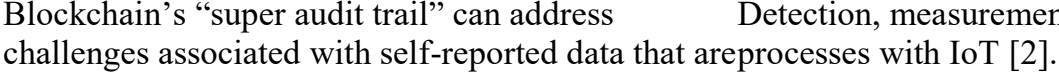
provided by supply chain partners.

Risk reduction Addressing the holistic sources of risk

Blockchain's ability to validate identities can be used to verify the provenance of items such as rough-cut diamonds and fine wines [7].

Only parties mutually accepted in the network can Validation of the identities of individuals engage in transactions in specific touchpoints.

Can ensure that software file downloaded has not been breached.

participating in transactions [1].

Foolproof method for confirmed identity can reduce cybersecurity-related risks [4]

Sustainability Verifying sustainability: possible to make indicators Validation of the identities of individuals related to sustainability more quantifiable and more participating in the supply chain [11]. meaningful.

Detection, measurement, and tracking of key SCM processes with IoT (e.g., [2], Provenance's use of mobile phones, blockchain and smart tagging, to track fish caught by fishermen)

Flexibility
Levels of network effects: Even if only a few participants use a blockchain solution, this will have a powerful effect. The power of this solution increases with the network effect.

Higher level of impact with deeper IoT integration All cases [1-11].

in logistics and supply chain

Can address consumers' concern about the source of Blockchain can deliver higher value when their food and beverages by providing indicators consumers become more concerned about the related to sustainability more quantifiable and more sources of their foods and beverages [11] meaningful. 
Several mechanisms are available to ensure cost reduction. In the supply chain, manual paperbased processes and humans carrying documents such as air courier expenses are eliminated. Maersk's case indicates that all the documents for shipping containers can be fully digitized and the containers can be tracked. The case of Everledger suggests that blockchain can make it easier to automate supply-chain certification processes. Modum's example makes it clear that blockchain makes it possible to allocate just the right amount of resources to perform shipping and other activities.

An observation is that unlike many other ICT systems such as RFID, blockchain can be deployed without devices, reading hardware or any process to attach tags to cases or pallets. Blockchain also combines unit level (instead of batch level) entity identification. Firms can exploit zero or very low marginal cost economics of digital networks. This combination is likely to bring transformation in supply chain. Thus it makes economic sense to generate a blockchain code even for small transactions. Even supply chain activities involving a small quantity of products such as dumping a few dozen pints of apples or blueberries into a juice press or pouring a mixture of liquid and solids into a strainer in order to remove the solids can be recorded in a cost-effective manner. Combining with data related to temperature, humidity, motion, chemical composition or other relevant indicators that can be collected from IoT devices or sensors on equipment, blockchain can cost-effectively confirm everything related to the supply chain history of food products (O’Marah, 2017).

Marginal costs associated with blockchain are thus zero or low, if technologies such as IoT have already been used to detect, measure, and track key SCM processes. To take one example, Walmart has accelerated the adoption of the IoT. In October 2016, it filed patent application, that describes the addition of IoT tags to products based on Bluetooth, RFID, infrared, NFC and other technologies. The tags will monitor product usage patterns and automatically refill orders. The IoT tags can also track products' expiration dates and product recalls (Alleven, 2017).

A caveat needs to be made about cost saving. Like many other technology projects, it may take a long time to materialize. For instance, Maersk expected that the costs are likely to reduce drastically, the blockchain-led savings are not expected to be known for two years or so until the technology is more widely used (Groenfeldt, 2017). When the rules are in place, blockchain could automate many processes and enable them to run more efficiently (Clancy, 2017).

Blockchain provides various mechanisms to assess and ensure quality. There are substantial frauds related to counterfeit products such as medicines, fine winesand luxury fashions. One estimate suggested that the value of fraudulent fine wine is about $\$ 1$ billion annually (Rothschield, 2016). According to Everledger, one-fifth of the sales of international "fine wine" are of counterfeit bottles (Mathieson, 2017). Managing the risks of counterfeiting is thus important in a number of industries. Industries that face the risks of counterfeiting are more likely to adopt blockchain in supply chain.

Blockchain can also help to guarantee quality of products with relevant data. The case of Modum makes it clear that by providing data related to indicators such as temperature, humidity, motion, light conditions, chemical composition from IoT devices or sensors on equipment, quality of a product can be guaranteed. 
Blockchain improves supply chain dependability by exerting pressure on supply chain partners to be more responsible and accountable for their actions. Gemalto's case indicates that individual responsibility and accountability can be stipulated and warranted. Note that in a conventional or "centralized" ledger, a single authority acts as the "trusted third party". In a blockchain system, each user has its own verified copy of the distributed ledger. A user can immediately see transactions on the ledger (Grant, 2017).

As noted above, some firms use self reported response from suppliers to assess the way environmental and social issues are tackled. A problem with this approach is that there are no mechanisms to verify the claims that a supplier makes. Blockchain's "super audit trail" can address this concern. Blockchain also provides the flexibility of being able to go back and examine the contents of the record for all the relevant parties in case of disputes.

The speed with which various operations are performed can be increased with blockchain. For instance, a faster rate can be achieved by digitizing physical processes and reducing interactions and communications.

The initial attempts to apply blockchain to supply chain, as one might expect, have been in addressing the holistic sources of risk (Everledger's use to verify the provenance of rough-cut diamonds). However, more cost- effective solutions are being explored, which is likely to lead to more widespread adoption of the technology to deal with atomistic sources of risk.

The roles of other mechanisms to reduce risks deserve mention. Only parties that are mutually accepted in the network can engage in transactions in specific touchpoints. It is thus possible to maintain trust and security. Lockheed Martin's case indicates that cybersecurity-related risks can be reduced with blockchain. The precision parts manufacturer Moog has launched a service called Veripart. As to the challenges that it wants to address, the director of Moog's additive manufacturing and innovation unit, James Regenor put the issue this way: "How can the maintenance crew on a U.S. aircraft carrier have absolute confidence that the software file they downloaded to 3D print a new part for a fighter jet hasn't been hacked by a foreign adversary?" (Casey \& Wong, 2017). This is a powerful argument in favor of blockchain. Without a proper solution to the trust problem, the IoT-driven economy may face a severe crisis.

A key application of blockchain is likely to be in verifying sustainability. A related development is that consumers are increasingly becoming concerned about the sources of their food and beverages (Scott, 2017). Using blockchain, it is possible to make indicators related to sustainability more quantifiable and more meaningful. In this way, blockchain has the potential to end unethical and illegal practices. Blockchain can also help ensure that the food consumers are eating is right and authentic (Kestenbaum, 2017).

Finally, using blockchain, a higher degree of flexibility can be achieved in supply chain. Flexibility can be defined as the supply chain's ability to the changing competitive environment in order to provide products and services in a timely and cost-effective manner (Swafford, Ghosh, \& Murthy, 2000). In prior literature researchers have used range and adaptability to measure flexibility. Range is related to how existing resources can be combined to achieve a 
number of different states (e.g., levels, options and positions). Adaptability can be defined as the ability to change from one state to another quickly and in a cost-effective way (D'Souza and Williams, 2000, Slack, 1983). In International supply chain, processes such as the letters of credit and bills of lading have very complex and intricate information flows. This means that even if only a few participants use a blockchain solution, this will have a powerful effect. The power of this solution increases with the network effect (Finextra, 2017).

In order to ensure the full traceability of goods, greater efforts and resources are being devoted to track all supply chain data using blockchain (Scott, 2017). In this regard, blockchain will benefit from an enriching IoT ecosystem, which is likely to make tracking possible and more accurate. A 2015 report from Cisco and DHL estimated that by the next decade, IoT in logistics and supply chain will generate $\$ 1.9$ trillion in value (DHL Trend Research \& Cisco Consulting Services, 2015). As noted above, Everledger's system did not track factors such as bottle temperature. With the development in IoT, temperature and other indicators can be tracked in a cost effective manner.

A key development is that consumers are increasingly becoming concerned about the source of their food and beverages (Scott, 2017). As noted above, blockchain can address consumers' concern about the source of their food and beverages by providing indicators related to sustainability more quantifiable and more meaningful.

\section{Discussion and implications}

In this paper, we developed a framework that considers how blockchain can help firms meet key SCM objectives. There is an interesting contrast here between the use of blockchain in the financial-industry and supply chain activities. Matt Levine, a Bloomberg View columnist asserted that users in the financial-industry could get "a lot of the same benefits" from a regular old database (Levine, 2017). He gives some examples to help illustrate this point. For instance, the Depository Trust Company, which is a clearing and settlement institution established in 1973 is a member of the Federal Reserve keeps a list of owners of stocks. To take another example, central banks keep "lists of who has what amounts of currency". In many cases, the problems that are encountered in supply chain-related activities concern issues related to communications. For instance, it is important to obtain numerous approvals from various authorities. They need to be communicated efficiently and in the same format. This is exactly the problem solved by blockchain in supply chain. The problem that blockchain is solving in Maersk's case is "a messaging problem" more than "a database problem". It is argued that the shipping-container example is different in the sense that whereas finance has trusted central intermediaries, shipping lacks such intermediaries. Due to the above-mentioned factors, it is argued that financial-industry blockchain projects are "highly hyped".

Using innovation diffusion theory, it can be argued that blockchain has a relative advantage in supply chain activities compared to in financial-industry. Note that relative advantage can be defined as perceived benefits of a technology over previous technologies and the extent to which it is better than the idea it supersedes (Rogers, 1995). One view is that there is not much value in setting up proprietary centralized blockchains for financial purposes, which do the same thing less efficiently than existing databases. Due to the absence of other available alternatives to solve 
the communications problem in shipping, blockchain is likely to become an attractive and costeffective option (Levine, 2017).

Security is an important consideration that may distinguish blockchain deployment in financial activities and supply chain. It was reported that the companies working with IBM were less worried about the security issues. Almost all of them were against an open system such as bitcoin. In this regard, in the blockchain world, permissionless and permissioned chains exist. A permissionless blockchain such as for bitcoin is an open platform. Anyone can join.

Permissioned blockchains, on the other hand, are restrictive. Access must be granted by some authority (Bussmann, 2017). An example is the supply chain blockchain developed by IBM and Maersk. This is a closed group of participants that are known and have permission to participate in the transaction (Groenfeldt, 2017). Despite some security-related issues, a private blockchain is expected to move faster than bitcoin (Popper \& Lohr, 2017).

Some determinants of blockchain adoption in supply chain are the number and capabilities of related actors involved and the extent of pressure faced by the firms to stay competitive. Partly because there is a challenge in bringing a large number of parties together, blockchain-based supply chain products are likely to be more appropriate for the tech and auto industries. Note that these industries exhibit shallow supply chain restricted to a small number of suppliers. Some consider garments industry as also possible targets. These industries have relatively shallow pool of suppliers, which is critical for blockchain platform's early stage of development. The oil industry, on the other hand, is reported to have up to 13 supplier layers (Del Castillo, 2017b). That's not to say that oil industry is likely to lag other sectors in the adoption of blockchain in supply chain. Indeed, some argue that the oil trading sector may overtake the financial sector in blockchain implementation. This sector is dominated by a few big players (players with strong capabilities). Some of them are large conglomerates and others are independent firms. They exhibit lower risk aversion than most financial institutions. If a few oil firms demonstrate positive results by moving their operations to blockchain platforms, others may follow them in order to be competitive. Moreover, firms in this sector are facing pressure to stay competitive since the market is facing an environment of lower profits (Acheson, 2017). In 2010, 16 companies that traded energy, metals and agriculture had aggregate revenues of $\$ 1.1$ trillion (Schneier, 2011).

Blockchain may also have important social and economic impacts. The coffee supply chain market employs 25 million people directly, mostly in rural areas of emerging countries. NGOs and others that monitor the fair-trade use "antiquated" techniques. Much superior and better results can be achieved with blockchain.

It is important for organizations to understand the problem they want to solve. This may require the cooperation of multiple participants (Clancy, 2017). A related point is that one entity's adoption of blockchain can have important impact on other supply chain entities. In some cases, companies can exert normative pressures on other supply chain members to influence their blockchain adoption. For instance, if a farmer registers food on blockchain, the distribution company that buys it from the farmer can also register. Everyone in the supply chain up to the grocer can do the same thing. 


\section{Challenges and limitations}

Despite the potentials noted above, however, blockchain has a number of major challenges to overcome. First, the global supply chain operates in a complex environment that requires various parties to comply with diverse laws, regulations and institutions. They include maritime laws and regulations, commercial codes, laws pertaining to ownership and possession of multiple jurisdictions in the shipping routes. Since international businesses operate against the backdrop of these established old laws, customs and institutions that are managed by human beings, implementing blockchain-based solutions can be an extremely complex task (Casey \& Wong, 2017). Addressing this challenge may be no small feat.

Second, implementation of blockchain consists of bringing all the relevant parties together, which can be a difficult undertaking in many cases. Everledger Founder and CEO Leanne Kemp noted that it took about 18 months to negotiate the relationships needed to make the Everledger service possible (Clancy, 2017).

Third, as to blockchain's potential to address fraudulent and manipulative activities, Matt Levine notes that the technology can provide a "robust way to make sure that the signatures are in order, the ownership information is up to date, and the inspections have been done". Regarding its limitations, he notes: "But if you then drill a hole in the container, take out all the teddy bears, and replace them with cocaine, the blockchain won't catch that. The blockchain is about taming all of the virtual attributes of the container, all of the paperwork that accompanies it. But the boundary between the physical and virtual worlds will always be a bit more lawless" (Levine, 2017).

Fourth, some technologists who like bitcoin think that the newer, corporate-designed blockchains lack one of the main elements that made bitcoin a success: the decentralized structure. For instance, anyone in the world is able to join bitcoin and study the ledgers. On the other hand, only a limited set of participants can have access to blockchain system like that of IBM. This feature can make such system more vulnerable to attack. For instance, a hacker can target a few of the participants. Despite a higher degree of decentralization of IBM's blockchain-based technology for tracking shipments compared to previous methods, it arguably "concentrates power in a handful of entities" (Popper \& Lohr, 2017).

Fifth, due to the requirement of high degree of computerization, not all countries are ready to participate in blockchain-based solutions. Many supply chain partners located in developing and least developed countries often are far from ready to adopt blockchain. Without their participation it is difficult to realize the full potential of blockchain in supply chain.

\section{Concluding remarks}

Supply chain activities are among the ones that are most likely to be transformed by blockchain. Among other things, blockchain facilitates valid and effective measurement of outcomes and performance of key supply chain processes. The food industry is most likely to be impacted by blockchain. The example of the 2015 E.coli outbreak at Chipotle Mexican Grill is illustrative of a widespread problem faced by the food supply chain. This example indicates that there is a deep 
thirst for dependable suppliers in the food industry. In this regard, a key element of blockchainbased model is that all the transactions are auditable, which is particularly important in gaining the trust of all interested parties. With blockchain, consumers know if the food they are eating is right and authentic. Various measures can be used to increase transparency in fish and seafood supply chains.

Blockchain can also help achieve robust cybersecurity measures. Trust and security can thus be improved with blockchain. At the same time, more resources need to be devoted to addressing concerns such as participation of diverse supply chain members and enrichment of the existing blockchain ecosystem in order to realize the full potential of blockchain.

\section{Acknowledgements}

The author is grateful to IJIM Regional Editor, Paul Solomon and anonymous reviewers for their generous, insightful and constructive comments on earlier versions, which helped to improve the paper drastically.

\section{References}

Acheson, N. (2017). Overtaking banking in the race to blockchain. CoinDesk. Retrieved from http://www.coindesk.com/overtaking-banking-race-blockchain/.

Alam, M. (2016). Why the auto industry should embrace Blockchain. CarTech. Retrieved from http://www.connectedcar-news.com/news/2016/dec/09/why-auto-industry-should-embraceblockchain/.

Allen, M. (2017). How blockchain could soon affect everyday lives. Retrieved from http://www.swissinfo.ch/eng/joining-the-blocks how-blockchain-could-soon-affect-everydaylives/43003266.

Alleven, M. (2017). Walmart looks to take on Amazon in the IoT. (May 5) Retrieved from http://www.fiercewireless.com/wireless/walmart-looks-to-take-amazon-iot.

Anderson, J. R. (1993). Rules of the mind. Mahwah, NJ: Lawrence Erlbaum.

Ansari, S., Garud, R., \& Kumaraswam, A. (2015). The disruptor's dilemma: TiVo and the U.S. television ecosystem. Strategic Management Journal, 37, 1829-1853.

Bünger, M. (2017). Blockchain for industrial enterprises: Hype, reality, obstacles and outlook. IoT Agenda. Retrieved from http://internetofthingsagenda.techtarget.com/blog/IoTAgenda/Blockchain-for-industrial-enterprises-Hype-reality-obstacles-and-outlook.

Baipai, P. (2017). How IBM and maersk will use the blockchain to change the shipping industry. Retrieved from http://www.nasdaq.com/article/how-ibm-and-maersk-will-use-the-blockchain-tochange-the-shipping-industry-cm756797. 
Baird, I. S., \& Thomas, H. (1991). What is risk anyway? Using and measuring risk in strategic management. In R. A. Bettis, \& H. Thomas (Vol. Eds.), Risk, strategy and management: 24. Connecticut: Jai Press Inc.

Bansal, P., \& Corley, K. (2012). Part 7: What's different about qualitative research? Academy of Management Journal, 55(3), 509-513.

Beske, P., Koplin, J., \& Seuring, S. (2008). The use of environmental and social standards by German first-tier suppliers of the Volkswagen AG. Corporate Social Responsibility \& Environmental Management, 15(2), 63-75.

Bettis, R. A., \& Mahajan, V. (1985). Risk/return performance of diversified firms. Management Science, 31(7), 785-799.

Bindi, T. (2017). Alibaba and AusPost team up to tackle food fraud with blockchain. http://www.zdnet.com/article/alibaba-and-auspost-team-up-to-tackle-food-fraud-withblockchain/.

Bowen, F. E., Cousins, P. D., Lamming, R. C., \& Faruk, A. C. (2001). The role of supply management capabilities in green supply. Production and Operations Management, 10(2), 174189.

Bussmann, O. (2017). BankThink A public or private blockchain? New Ethereum project could mean both. American Banker. [Retrieved from] https://www.americanbanker.com/opinion/apublic-or-private-blockchain-new-ethereum-project-could-mean-both.

Campbell, R. (2016). Modum.io's tempurature-tracking blockchain solution wins accolades at kickstarter accelerator 2016. Bitcoinmagazine. Retrieved from https://bitcoinmagazine.com/articles/modum-io-s-tempurature-tracking-blockchain-solutionwins-accolades-at-kickstarter-accelerator-1479162773/.

Casey, M. J., \& Wong, P. (2017). Global supply chains are about to get better, thanks to blockchain. Harvard business review https://hbr.org/2017/03/global-supply-chains-are-about-toget-better-thanks-to-blockchain.

Christidis, K., \& Devetsikiotis, M. (2016). Blockchains and smart contracts for the internet of things. IEEE Access, 4, 2292-2303.

Clancy, H. (2017). The blockchain's emerging role in sustainability. GreenBiz. Retrieved from https://www.greenbiz.com/article/blockchains-emerging-role-sustainability.

Coggine, A. (2017). Walmart to track delivery drones with blockchain, soon to accept bitcoin? June 07 https://cointelegraph.com/news/walmart-to-track-delivery-drones-with-blockchain-soonto-accept-bitcoin.

Cognizant Reports (2016). Blockchain in banking: A measured approach. 
Constantino, S., \& Westberg, K. (2009). "Using triangulation and multiple case studies to advance relationship marketing theory”. Qualitative Market Research An International Journal, 12,3 .

cointelegraph. com (2017). IBM. maersk to deliver first blockchain project by end of 2017. 7. https://cointelegraph.com/news/ibm-maersk-to-deliver-first-blockchain-project-by-end-of-201.

D’Souza, D. E., \& Williams, F. P. (2000). Toward a taxonomy of manufacturing flexibility dimensions. Journal of Operations Management, 18, 577-593.

DHL Trend Research, \& Cisco Consulting Services (2015). Internet Of Things In Logistics: A collaborative report by DHL and Cisco on implications and use cases for the logistics industry.

De Jesus, C. (2016). Walmart is using blockchain to find contaminated food sources. November 21, 2016, Retrieved from https://futurism.com/walmart-is-using-blockchain-to-findcontaminated-food-sources/.

Del Castillo, M. (2017a). Intel demos seafood tracking on sawtooth lake blockchain. CoinDesk. Retrieved from http://www.coindesk.com/intel-demos-seafood-tracking-sawtooth-lakeblockchain/.

Del Castillo, M. (2017b). Foxconn reveals plan for blockchain supply chain domination. Retrieved from http://www.coindesk.com/foxconn-wants-take-global-supply-chain-blockchain/.

Eisenhardt, K. M., \& Graebner, M. E. (2007). Theory building from cases: Opportunities and challenges. Academy of Management Journal, 50(1), 25-32.

Eppler, M. J. (2006). Managing information quality: Increasing the value of information in knowledge-intensive products and processes. Berlin: Springer.

Finextra (2017). Banking on blockchain: Charting the progress of distributes ledger technology in financial services, 2016. A finextra white paper. Produced in Association with IBM.

Flint, D. (2004). Strategic marketing in global supply chains: Four challenges. Industrial Marketing Management, 33, 45-50.

Glaser, B. G., \& Strauss, A. L. (1967). The discovery of grounded theory: Strategies for qualitative research. Chicago: Aldine.

Goldbach, M., Seuring, S., \& Back, S. (2003). Coordinating sustainable cotton chains for the mass market -The case of the German mail order business OTT. Greener Management International, 43, 65-78.

Golder, P. N. (2000). Historical method in marketing research with new evidence on long-term market share stability. Journal of Marketing Research, 37(2), 156-172. 
Gottschalk, L. (1969). Understanding history: A primer of historical method. New York: Alfred A. Knopf.

Grant, S. (2017). Blockchain and secured lending in Canada. JDSupra. Retrieved from http://www.jdsupra.com/legalnews/blockchain-and-secured-lending-in-canada-66699/.

Greene, D., \& David, J. L. (1984). A research design for generalizing from multiple case studies. Evaluation and Program Planning, 7, 73-84.

Groenfeldt, T. (2017). IBM and maersk apply blockchain to container shipping. Forbes. Retrieved from https://www.forbes.com/sites/tomgroenfeldt/2017/03/05/ibm-and-maersk-applyblockchain-to-container-shipping/.

HIQA (2011). International review of data quality health information and quality authority (HIQA). http://www.hiqa.ie/press-release/2011-04-28-international-review-data-quality (Accessed 09 June 2016).

Hannam, K. (2017). This emerging tech company has put Asia's tuna on the blockchain. http://www.forbes.com/sites/keshiahannam/2016/09/30/this-emerging-tech-company-has-putasias-tuna-on-the-blockchain/\#5805220a2ea6.

Higgins, S. (2017a). Walmart: Blockchain food tracking test results are 'very encouraging'. June 5 http://www.coindesk.com/walmart-blockchain-food-tracking-test-results-encouraging/.

Higgins, S. (2017b). Defense giant lockheed martin integrates blockchain. CoinDesk. Retrieved from http://www.coindesk.com/defense-giant-lockheed-martin-integrates-blockchain/.

Jackson, B. (2017). Canada's first commercial blockchain service could become the 'Interac' for digital transactions. Canada: IT World. http://www.itworldcanada.com/article/canadas-firstcommercial-blockchain-service-could-become-the-interac-for-digital-transactions/391673.

Kestenbaum, R. (2017). Why Bitcoin is important for your business. Forbes. Retrieved from https://www.forbes.com/sites/richardkestenbaum/2017/03/14/why-bitcoin-is-important-for-yourbusiness/3/\#2da6d4c72b3b.

Kharif, O. (2016). Wal-Mart tackles food safety with trial of blockchain. Bloomberg. Retrieved from https://www.bloomberg.com/news/articles/2016-11-18/wal-mart-tackles-food-safety-withtest-of-blockchain-technology.

Kimberly Process, 2016, Retrieved from https://www.kimberleyprocess.com/.

Koetsier, J. (2017). Blockchain Beyond Bitcoin: How Blockchain Will Transform Business in 3 5 Years. June 14 https://www.inc.com/john-koetsier/how-blockchain-will-transform-business-in3-to-5-years.html. 
Kolodny, L. (2017). Bext360 is using robots and the blockchain to pay coffee farmers fairly. TechCrunch https://techcrunch.com/2017/04/11/bext360-is-using-robots-and-the-blockchain-topay-coffee-farmers-fairly/.

Koplin, J., Seuring, S., \& Mesterharm, M. (2007). Incorporating sustainability into supply management in the automotive industry: The case of the Volkswagen AG. Journal of Cleaner Production, 15(11-12), 1053-1062.

Kovács, G. (2004). Framing a demand network for sustainability Progress in Industrial Ecology. An International Journal, 2004, 397-410.

Kshetri, N. (2016a). Creation, deployment, diffusion and export of Sub-Saharan Sfricaoriginated information technology-related innovations. International Journal of Information Management, 36(6), 1274-1287 Part B.

Kshetri, N. (2016b). Big data's role in expanding access to financial services in China. International Journal of Information Management, 36(3), 297-308.

Kshetri, N. (2017a). Can blockchain strengthen IoT? IEEE IT Professional, 19(4), 68-72.

Kshetri, N. (2017b). Blockchain's roles in strengthening cybersecurity and protecting privacy. Telecommunications Policy forthcoming.

Levine, M. (2017). Cargo blockchains and Deutsche bank. Retrieved from https://www.bloomberg.com/view/articles/2017-03-06/cargo-blockchains-and-deutsche-bank.

Linton, J. D., Klassen, R., \& Jayaraman, V. (2007). Sustainable supply chains: An introduction. Journal of Operations Management, 25(6), 1075-1082.

Mainelli, M. (2017). Blockchain will help us prove our identities in a digital world. Harvard business review. Retrieved from https://hbr.org/2017/03/blockchain-will-help-us-prove-ouridentities-in-a-digital-world.

Manuj, I., \& Mentzer, J. T. (2008). Global supply chain risk management. Journal of Business Logistics, 29(1), 133-155.

Mason, R. O., McKenney, J. L., \& Copeland, D. G. (1997). An historical method for MIS Research: Steps and assumptions. MIS Quarterly, 21(3), 307-320.

Mathieson, M. A. (2017). Blockchain starts to prove its value outside of finance. Computer weekly http://www.computerweekly.com/feature/Blockchain-starts-to-prove-its-value-outsideof-finance.

Mentzer, J. T., Flint, D. J., \& Hult, G. T. M. (2001). Logistics service quality as a segmentcustomized process. Journal of Marketing, 65(4), 82-104. 
Meyer, A., \& Hohmann, P. (2000). Other thoughts; other results? -Remei's bioRe organic cotton on its way to the mass market. Greener Management International, 59-70.

Nation, J. (2017). Walmart tests food safety with blockchain traceability. June 1 . Retrieved from https://www.ethnews.com/walmart-tests-food-safety-with-blockchain-traceability.

O’Marah, K. (2017). Blockchain: Enormous potential demands your attention. Supply Chain Digital. Retrieved from http://www.supplychaindigital.com/technology/blockchain-enormouspotential-demands-your-attention.

PWCHK.com (2016). Blockchain the biggest disruptor to industries since the introduction of the Internet-PwC. 2016. http://www.pwchk.com/home/eng/pr 070716.html.

Popper, N., \& Lohr, S. (2017). Blockchain: A better way to track pork chops, bonds, bad peanut butter? https://www.nytimes.com/2017/03/04/business/dealbook/blockchain-ibm-bitcoin.html.

Price, R. J., \& Shanks, G. (2005). Empirical refinement of a semiotic information quality framework. Proceedings of 38th Hawaii International Conference on System Sciences pp. 1-10.

Prnewswire (2017). Pharma companies tap startups to develop protocol for tracking and verifying prescription drugs using blockchain. http://www.prnewswire.com/newsreleases/pharma-companies-tap-startups-to-develop-protocol-for-tracking-and-verifyingprescription-drugs-using-blockchain-300428313.html.

Quak, H. J., \& de Koster, M. B. M. (2007). Exploring retailers' sensitivity to local sustainability policies. Journal of Operations Management, 25, 1103-1122.

Rao, P., \& Holt, D. (2005). Do green supply chains lead to competitiveness and economic performance? International Journal of Operations \& Production Management, 25(9), 898-916.

Rogers, E. M. (1995). Diffusion of innovations (4th ed.). New York: Free Press.

Rothschield, C. F. (2016). Wine vault offers security in a digital age. Wine Searcher http://www.wine-searcher.com/m/2016/12/wine-vault-offers-security-in-a-digital-age.

Rowley, J. (2002). Using case studies in research. Management Research News, 25(1), 16-27.

Schneier, J. (2011). Corrected: Commodity traders: The trillion dollar club. Reuters http://www.reuters.com/article/us-commodities-houses-idUSTRE79R4S320111028.

Scott, M. (2017). Innovation percolates when coffee meets the blockchain. Nasdaq http://www.nasdaq.com/article/innovation-percolates-when-coffee-meets-the-blockchain$\underline{\mathrm{cm} 774790}$. 
Seawright, J., \& Gerring, J. (2008). Case-selection techniques in case study research a menu of qualitative and quantitative options. Political Research Quarterly, 61(2), 294-308.

Slack, N. (1983). Flexibility as a manufacturing objective. International Journal of Operations and Production Management, 7(4), 35-45.

Stvilia, B., Gasser, L., Twidale, M. B., \& Smith, L. C. (2007). A framework for information quality assessment. Journal of the American Society for Information Science and Technology, 58.

Svensson, G. (2000). A conceptual framework for the analysis of vulnerability in supply chains. International Journal of Physical Distribution and Logistics Management, 30(9), 731-749.

Swafford, P., Ghosh, S., \& Murthy, N. (2000). A model of global supply chain agility and its impact on competitive performance. Proceedings of the 31st national DSI meeting (pp. 10371039).

Tapscott, D. (2016). How will blockchain change banking? How won't it? http://www.huffingtonpost.com/don-tapscott/how-will-blockchain-chang b 9998348.html.

Trowbridge, P. (2001). A case study of green supply-chain management at advanced micro devices. Greener Management International, 35, 121-135.

Van Maanen, J., Dabbs, J. M., \& Faulkner, R. R. (1982). Varieties of qualitative research. Beverly Hills, CA: Sage.

WEF [World Economic Forum] (2015). Deep shift technology tipping points and societal impact survey report. Retrieved from http://www3.weforum.org/docs/WEF GAC15 Technological Tipping Points report 2015.pdf.

Wang, R. Y., \& Strong, D. M. (1996). Beyond accuracy: What data quality means to data consumers. Journal of Management Information Systems, 12, 5-33.

Whetten, D. A. (1989). What constitutes a theoretical contribution? Academy of Management Review, 14(4), 490-495.

White, G. P. (1996). A survey and taxonomy of strategy-related performance measures for manufacturing. International Journal of Operations \& Production Management, 16(3), 42-61.

Whyte, W. F. (1984). Learning from the field: A guide from experience. Sage: Beverly Hills, CA.

Yiannas, F. (2017). A new era of food transparency with Wal-Mart center in China. Food safety news. Retrieved from http://www.foodsafetynews.com/2017/03/a-new-era-of-food-transparencywith-wal-mart-center-in-china/\#.WOB65mcVjIU. 
Yin, R. (1994). Case study research: design and methods (2nd ed.). Newbury Park: CA: Sage. 